\title{
Is Metformin a Treatment Opportunity for Colorectal Cancer?
}

\author{
Ezgi Erogluำ Ozge Uzun ${ }^{2}$ \\ ${ }^{1}$ Department of Pharmacology, Eskisehir Osmangazi University, Eskisehir, Turkey. \\ ${ }^{2}$ Department of Pharmacology, Okan University, Istanbul, Turkey.
}

\section{ABSTRACT}

\section{BACKGROUND}

Colorectal cancer (CRC) is one of the common deadly cancers worldwide. The incidence of CRC has been increasing nowadays and new therapy agents are still being investigated for the treatment. Metformin (1,1-dimethyl biguanide), an oral antidiabetic drug from Galega officinalis mostly used in the treatment of type 2 diabetes, has gained considerable research interest in cancer prevention and therapy for many types of cancer including CRC. By targeting the specific pathways involved in cell differentiation, metabolism and metastasis, different mechanisms of action of metformin are tried to be elucidated using CRCs in studies.

\section{METHODS}

We searched 3 electronic bibliographic databases (Web of Science, PubMed, and Google Scholar) and research in progress using ClinicalTrials.gov from inception to September 20, 2019. Subject headings and key words included 'metformin' and/or 'metformin in colon cancer', and related terms, and various terms related to colon cancer treatment.

\section{RESULTS}

Although it seems justified on the basis of the results of a large number of studies, there is much we do not know about the effect of metformin on CRC.

\section{CONCLUSIONS}

In this review, we focused on studies showing the potential effects of metformin in CRC, especially its possible mechanisms of action in chemoprevention therapy for colorectal cancers.

\section{KEY WORDS}

Metformin, Colorectal Cancer, Anti-Cancer Drugs, Anti-Diabetic Drugs
Corresponding Author:

Ezgi Eroglu,

Eskisehir Osmangazi University,

Faculty of Medicine,

Department of Pharmacology,

Eskisehir-26480, Turkey.

E-mail:ezgbzkrt@gmail.com

DOI: $10.14260 /$ jemds/2020/172

Financial or Other Competing Interests: None.

How to Cite This Article:

Eroglu E, Uzun O. Is metformin a treatment opportunity for colorectal cancer? J. Evolution Med. Dent. Sci. 2020;9(10):792797, DOI: 10.14260/jemds/2020/172

Submission 03-01-2020,

Peer Review 14-02-2020,

Acceptance 22-02-2020,

Published 09-03-2020.

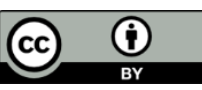


Colorectal cancer (CRC) is third most deadly cancer type in the world and the incidence of CRC has been increasing in many countries.(1) Several conventional chemotherapy regimens have been widely used in the treatment of CRC patients.(2) Nevertheless, chemotherapy-induced toxicity may limit this treatment in patients. So, it is crucial to identify new therapeutic approaches in combination with traditional therapy to specifically target and eliminate all cancer cells...(3)

Metformin (1, 1-dimethylbiguanide), a first-line antidiabetic, is being prescribed to over 150 million people in the world at the present time.(4) It lowers blood glucose concentrations without causing hypoglycaemia and also reduces insulin resistance and plasma fasting insulin level.(5) Interestingly in addition to its metabolic effects, studies also have shown that metformin may be beneficial for cancer treatment due to anti-cancer properties.(6) The first study about metformin and cancer by Evans et al showed that the incidence of general cancer was lower in patients metformintreated patients than other drugs-treated patients.(7) Since this study a considerable amount of in vivo and in vitro, randomised studies and ongoing clinical trials have indicated that metformin has an antitumour effect in CRCs. Moreover, many studies demonstrated that combined treatment of metformin with other chemotherapeutic and targeted agents synergistically increases the anticancer effect. Taken together, these results propound that metformin may become an alternative adjuvant treatment option for CRC.

A vast number of pre-clinical and clinical studies have suggested that metformin alone or in combination with other chemotherapeutic agents might be useful in the treatment of different forms of CRC. In the current review, we discuss the biology and clinical usage of metformin, the cellular, preclinical, and clinical studies that have researched and the possible mechanisms as a potential anti-cancer agent in CRC.

\section{Metformin}

Metformin (N-N-dimethybiguanide hydrochloride, Figure 1) is one of the first preferred oral glucose lowering agents to manage type 2 diabetes.(8) The herbal line of metformin is based on the use of Galega officinalis (also known as French lilac, goat's rue) in Europe.(9) Metformin was first discovered in 1922 by Emile Werner and James Bell.(10) This compound is effective in reducing the amount of glucose in rabbits and dogs, in contradistinction to other similar compounds, it does not affect heart rate and blood pressure.(11,12) In 1957, the doctor Jean Sterne conducted the first clinical trials of metformin and notified the use of metformin to treat diabetes.(13) Metformin reduces basal glucose output by suppressing glycogenolysis and gluconeogenesis in the liver, and by enhancing glucose uptake in muscles. Moreover, metformin does not directly stimulate insulin secretion.(14) A great number of studies have been expanded to evaluate metformin as an optional treatment potential for polycystic ovary syndrome as well as its antiaging, cardiovascular protective and neuroprotective effects.(15-18) In recent years, several epidemiological, preclinical and clinical studies shed light on the anticancer role of metformin consistently. Studies on various cancer models, including colon, breast, and prostate have indicated the effect of metformin in CSCs by targeting multiple specific pathways involved in metabolism, cell differentiation, regeneration, and metastasis.(19)

$$
\begin{array}{|l|l|l|}
\hline & \begin{array}{l}
\text { Figure 1. } \\
\text { Molecular Structure of Metformin }
\end{array} \\
\hline
\end{array}
$$

\section{Cellular and Pre-Clinical Data}

The results of in vivo and in vitro studies in mice and rats confirm that metformin may be an alternative agent in the treatment of colon cancer. Buzzai et al. observed that metformin delayed tumour onset in mice models for p53 mutant colon cancer. It has been found to be selectively toxic in p53 deficient cells (HCT116 p53-/- xenografts) and provides a potential mechanism for decreasing tumour incidence in patients treated with metformin.(20) In another study metformin has been demonstrated to have growth inhibitory effects in prostate (PC-3) and colon cancer (HT-29) cell lines.(21) A study in China showed that the combined use of metformin and vitamin D3 considerably decreases the development of colorectal neoplasia in two colorectal carcinogenesis rodents models and Vitamin D3 increased the chemo preventive effects of metformin in these models. Metformin enhanced also the chemo preventive effects of vitamin D3.(22) A study about anticancer effects of metformin demonstrated that metformin supressed the azoxymethane (AOM)-induced development of aberrant crypt foci (ACF), a marker of $\mathrm{CRC}$, in $\mathrm{BALB} / \mathrm{c}$ mice and respectively the polyp growth is supressed by metformin in ApcMin/+ mice. Inhibition of mTOR phosphorylation was showed in colon cancer models.(23) A study in 2013 showed that metformin might be beneficial in the treatment of IL1 $\beta$-induced colon carcinogenesis.(24) Nangia-Makker et al. presented that the combined treatment of metformin and other chemotherapeutic agents inhibited cell growth and colonosphere formation in chemo resistant colon cancer cells and it may be an effective treatment regimen for recurrent CRC.(25) Zhang $Y$ et al reported the synergistic effect of metformin and 5-Fluorouracil (5-FU) on the proliferation of human colorectal cancer cell line (SW620) and they showed that metformin in combination with 5-FU remarkably inhibited the proliferation of CSCs. (26) The anticancer effect of metformin on 1,2-dimethylhydrazine (DMH)-induced colon tumour adenocarcinomas were studied in non-diabetic rats and it was found that metformin decreased the invasiveness of colon carcinomas.(27) The effects of metformin on colon cancer were researched in diabetic and non-diabetic mice and it markedly decreased histopathological scores in diabetic mice colons.(28) The proliferation of precancerous lesions in colonic tissues was significantly reduced following metformin treatment in diabetic rats. Moreover, metformin also reduced the imbalance between glycolysis and oxidative phosphorylation and reverse the Warburg effect.(29) Geagea et al. showed the synergetic effects of metformin and rapamycin in association with the probiotics caused to decreased expression of early lesions in CRC such as ACF in mice with xenografts.(30) 


\section{Clinical Data and Trials}

Randomized controlled studies and clinical trials conclude that successful conversion of metformin into clinical practice can be crucial. The first large cohort study was conducted in Tayside, Scotland and this study showed that in diabetic patients receiving metformin, the overall risk of cancer was reduced compared to those receiving other diabetes treatments. This study significantly increased scientific concern in this area, and numerous studies have confirmed its effectiveness in CRC chemoprevention.(7) Since then, several epidemiologic studies showed that lower colon cancer risk in diabetic patients treated with metformin than in non-metformin users. A pilot study was conducted in Japan to assess the anticancer effect of metformin on ACF and the results of this study showed that the metformin group had a significant reduce in the mean number of ACF, whereas the mean ACF number did not change remarkably in the nontreatment group. (31) In another study Lee et al conducted a prospective cohort study in diabetic patients from Taiwan treated with or without metformin and this study showed that metformin was able to reduce incidence rates of CRC and hepatocellular carcinoma (HCC) approximate the levels of non-diabetic patients. However, there was a considerable gender difference with metformin in CRC which advantaged women.(32) Additionally, in a large case-control study of US patients with diabetes, they found remarkable reduced risk of developing CRC with any previous or current metformin use. (33) A retrospective cohort study conducted by Currie et al. in diabetic patients treated metformin, sulfonylurea or insulin, metformin taking patients had the lowest risk of developing colorectal or pancreatic cancer. Adding metformin to insulin treatment reduced cancer progression, whereas insulin alone therapy enhanced the risk of colorectal cancer.(34) In a retrospective study of Korean patients with CRC and type 2 diabetes, metformin therapy had a lower risk of CRC and allcause mortality.(35) A retrospective study demonstrated that US patients having type 2 diabetes and CRC had higher survival of 76.9 months treated with metformin as compared with 56.9 months in not-treated with metformin.(36) A total of 30,493 Danish patients of which 3391 diagnosed with diabetes and 1962 were treated with metformin and it was found that metformin is related with significant reduce in allcause mortality compared with patients with diabetes not treated with metformin. (37) A case-control study of incident CRCs was conducted in Danish people with type 2 diabetes and they observed that an indication of a chemo protective effect of long-term metformin use for CRC in only diabetics women.(38) A cohort study was examined variable levels of metformin exposure and connections with colorectal cancerspecific mortality and it was found that significant associations were determined only for metformin use in the diabetic cohort.(39) There are currently 7 ongoing or upcoming clinical studies evaluating the place of metformin in the colorectal cancer (table 1). The results obtained from these clinical studies will evaluate the importance of metformin in the prevention and therapy of CRC and allow the determination of future targets.

\section{Potential Mechanisms of Metformin in CRC}

The mechanisms underlying the antineoplastic potential of metformin for colorectal cancer have not yet been fully understood. Metformin can inhibit tumourigenesis in various cancers and tumours by different signalling pathways.

\begin{tabular}{|c|c|c|c|}
\hline Study & $\begin{array}{l}\text { Clinical } \\
\text { Trials.gov } \\
\text { İdentifier } \\
\end{array}$ & Conditions & Interventions \\
\hline \begin{tabular}{|c|}
$\begin{array}{c}\text { Metformin Plus Irinotecan } \\
\text { for Refractory Colorectal } \\
\text { Cancer }\end{array}$ \\
\end{tabular} & NCT01930864 & $\begin{array}{c}\text { Colorectal } \\
\text { Neoplasms; } \\
\text { Adenocarcinoma }\end{array}$ & $\begin{array}{l}\text { Drug: metformin } \\
\text { Drug: irinotecan }\end{array}$ \\
\hline \begin{tabular}{|c|} 
A Randomized, $2 \times 2$ \\
Factorial Design Biomarker \\
Prevention Trial of Low- \\
dose Aspirin and \\
Metformin in Stage I-III \\
Colorectal Cancer Patients.
\end{tabular} & NCT03047837 & $\begin{array}{l}\text { Tertiary Prevention } \\
\text { in Colon Cancer }\end{array}$ & $\begin{array}{c}\text { Drug: Aspirin } \\
\text { (ASA)+Metformin } \\
\text { (MET) } \\
\text { Drug: ASA } \\
\text { Drug: MET } \\
\text { Drug: Placebos }\end{array}$ \\
\hline \begin{tabular}{|c|} 
Effect of Adjunctive \\
Metformin on Recurrence \\
of Non-DM Stage III \\
Colorectal Cancer: Open \\
Label Randomized \\
Controlled Study \\
\end{tabular} & NCT02614339 & $\begin{array}{l}\text { Non-DM Stage III } \\
\text { Colorectal Cancer }\end{array}$ & $\begin{array}{l}\text { Drug: metformin } \\
\text { Drug: control }\end{array}$ \\
\hline $\begin{array}{l}\text { Metformin Treatment for } \\
\text { Colon Cancer }\end{array}$ & NCT03359681 & Colon Cancer & $\begin{array}{l}\text { Drug: Metformin } \\
\text { Hydrochloride } \\
\text { Drug: Placebo } \\
\text { oral capsule }\end{array}$ \\
\hline $\begin{array}{c}\text { Nivolumab and Metformin } \\
\text { in Patients with Treatment } \\
\text { Refractory MSS Colorectal } \\
\text { Cancer }\end{array}$ & NCT03800602 & \begin{tabular}{|c|} 
Colorectal \\
Adenocarcinoma; \\
Metastatic \\
Microsatellite Stable \\
Colorectal Carcinoma; \\
Refractory Colorectal \\
Carcinoma; \\
Stage IV, IVA, IVB, \\
IVC Colorectal \\
Cancer; Colorectal \\
Cancer Metastatic \\
\end{tabular} & $\begin{array}{l}\text { Drug: Metformin } \\
\text { Biological: } \\
\text { Nivolumab }\end{array}$ \\
\hline $\begin{array}{c}\text { Metformin with } \\
\text { Neoadjuvant Chemo } \\
\text { radiation to Improve } \\
\text { Pathologic Responses in } \\
\text { Rectal Cancer } \\
\end{array}$ & NCT03053544 & $\begin{array}{l}\text { Rectal Neoplasm } \\
\text { Carcinoma in Situ } \\
\text { Adenocarcinoma }\end{array}$ & Drug: Metformin \\
\hline \begin{tabular}{|c|} 
The Chemo preventive \\
Effect of Metformin in \\
Patients with Familial \\
Adenomatous Polyposis: \\
Double Blinded \\
Randomized Controlled \\
Study \\
\end{tabular} & NCT01725490 & $\begin{array}{l}\text { Familial } \\
\text { Adenomatous } \\
\text { Polyposis }\end{array}$ & $\begin{array}{l}\text { Drug: Metformin } \\
\text { Drug: Placebo }\end{array}$ \\
\hline \multicolumn{4}{|c|}{$\begin{array}{c}\text { Table 1. The Ongoing and Upcoming Clinical Trials with Metformin } \\
\text { in Colorectal Cancer Prevention and Therapy }\end{array}$} \\
\hline $\begin{array}{l}{ }^{*} \text { A registry and results dat } \\
\text { of human participants con } \\
\text { www.ClinicalTrials.gov }\end{array}$ & $\begin{array}{l}\text { abase of privately } \\
\text { ducted around th }\end{array}$ & $\begin{array}{l}\text { y and publicly supporte } \\
\text { ee world. Available onlir }\end{array}$ & $\begin{array}{l}\text { ed clinical studies } \\
\text { ne: }\end{array}$ \\
\hline
\end{tabular}

\section{The İnsulin Growth Factor (IGF) Pathway}

Several studies have shown that anticancer action of metformin is related to the disruption of insulin signalling. Insulin-like growth factor (IGF) is a growth hormone playing a key role in normal growth and development. IGF signalling pathway is consist of three ligands (IGF-1, IGF-2, and insulin), three receptors [IGF-1 receptor (IGF-1R), IGF-2R, and insulin receptor (IR)].(40) IGF-1 not only affects cell proliferation, survival and differentiation, but also genetic damage in healthy cells, therefore IGF-1 plays a critical role in the development of cancer.(41) Epidemiologic studies have shown a possible association between IGF level and the development of solid tumours such as colon, prostate and breast cancer. ${ }^{(42)}$ Furthermore, metformin is known to inhibit IGF-1R activation through the phosphatidylinositol-4,5bisphosphate 3-kinase (PI3K)/protein kinase B (Akt) pathway.(43) Metformin has been presented to reduce the risk of colon cancer by targeting the IGF pathway (44) and previous studies have demonstrated that metformin down regulated intratumoural IGFR-I in CRC (28) 


\section{AMPK Pathway}

The adenosine monophosphate-activated protein kinase (AMPK) is a excessively conserved heterotrimeric kinase, which is considered to be one of the main regulators of cellular energy status and key cellular processes and liver kinase B1 (LKB1) is a well-conserved kinase, required for AMPK activation.(45) One of the potential anti-cancer mechanisms of metformin is the activation of AMPK inhibits energy consuming pathways and protein synthesis, metformin has been proposed to inhibit cell proliferation through AMPK.(46) Metformin activates the AMPK pathway in normal and cancer cells. Studies in animal models show that metformin induces AMPK signalling cascade and inhibits tumour growth and colon tumour formation, $(21,23,47)$ and also studies in cell lines have reported that metformin reduces cell proliferation in colon cancer by AMPK activation.(48) Metformin treatment also activated AMPK regulates $\beta$-catenin to decrease cell proliferation in human colon carcinoma RKO cells.(49) It is known that activated AMPK inhibits the synthesis of important proteins mediated by mTOR. The phosphatidylinositol-3-kinase (PI3K)/Akt/mTOR pathway is activated for proliferation of CSCs; thus, the mechanism of action of metformin-induced CSC suppression involves the activation of AMPK and the sequential inactivation of mTOR.(50) In a study, metformin prevented inflamed colorectal epithelial cells and cancer cells by activating the LKB1/AMPK pathway.(51) On the other hand, metformin can inhibits the mTOR pathway in an AMPKindependent pathway by inactivating Rag GTPases.(52)

\section{Other Mechanisms}

The data from several studies have shown that the antitumour activity of metformin might be as an antiinflammatory agent in some cancer types via inhibition of the nuclear factor-kappa B (NF- $\mathrm{BB}$ ) signalling pathway. In a study metformin inhibited initial cellular transformation and suppresses colon cancer stem cells via inhibition of NF- $\kappa B$ function by blocking a specific signal transduction pathway.(53) Sena et al. also demonstrated that metformin has an antiproliferative effect relevant to changes in the expression of Nuclear factor E2-related factor 2 (NRF-2)/NF$\kappa \mathrm{B}$ pathways, additionally an apoptotic effect on human colon cancer cells.(54) Numerous studies have indicated that the antitumour effect of metformin may be due to a relationship between metformin and immune cells. In another study metformin inhibited IL-6-induced epithelial-mesenchymal transition signalling by inhibiting STAT3 phosphorylation in colon cancer lines. ${ }^{(55)}$

\section{CONCLUSIONS}

The current review describes the potential use and mechanisms of action of metformin as a chemotherapeutic agent for CRC based on pre-clinical and clinical studies. Evidences in these studies suggest beneficial effects of metformin in reducing the risk of CRC. On the other hand, more long-term randomized trials with different target population are needed to investigate the role of metformin in CRC treatment and its possible use as an anticancer agent in clinical practice. A better understanding of metformin as a potential chemotherapeutic drug in colon cancer will provide better information for its use as an effective anticancer agent for CRC treatment.

\section{REFERENCES}

[1] Ferlay J, Soerjomataram I, Dikshit R, et al. Cancer incidence and mortality worldwide: sources, methods and major patterns in GLOBOCAN 2012. Int J Cancer 2015;136(5):E359-86.

[2] Venugopal A, Stoffel EM. Colorectal cancer in young adults. Curr Treat Options Gastroenterol 2019;17(1):8998.

[3] Parizadeh SM, Jafarzadeh-Esfehani R, Hassanian SM, et al. Targeting cancer stem cells as therapeutic approach in the treatment of colorectal cancer. Int J Biochem Cell Biol 2019;110:75-83.

[4] He L, Meng S, Germain-Lee EL, et al. Potential biomarker of metformin action. J Endocrinol 2014;221(3):363-9.

[5] Viollet B, Guigas B, Garcia NS, et al. Cellular and molecular mechanisms of metformin: an overview. Clin Sci (Lond) 2012;122(6):253-70.

[6] Quinn BJ, Kitagawa H, Memmott RM, et al. Repositioning metformin for cancer prevention and treatment. Trends Endocrinol Metab 2013;24(9):469-80.

[7] Evans JM, Donnelly LA, Emslie-Smith AM, et al. Metformin and reduced risk of cancer in diabetic patients. BMJ 2005;330(7503):1304-5.

[8] Saraei P, Asadi I, Kakar MA, et al. The beneficial effects of metformin on cancer prevention and therapy: a comprehensive review of recent advances. Cancer Manag Res 2019;11:3295-313.

[9] Bailey CJ. Metformin: historical overview. Diabetologia 2017;60(9):1566-76.

[10] Werner EA, Bell J. The preparation of methylguanidine, and of $\beta \beta$-dimethylguanidine by the interaction of dicyandiamide and methylammonium and dimethylammonium chlorides respectively. J Chem Soc Trans 1922;121:1790-4.

[11] Hesse G, Taubmann G. Die Wirkung des Biguanids und seiner Derivate auf den Zuckerstoffwechsel. NaunynSchmiedebergs. Arch Exp Path Pharmacol 1929;142:290-308.

[12] Slotta KH, Tschesche R. Uber Biguanide. II. Die blutzuckersenkende Wirkung der Biguanides. Ber Dtsch Chem Ges B: Abh. 1929;62:1398-405.

[13] Sterne J. Du nouveau dans les antidiabétiques. La NN diméthylamino guanyl guanidine (NNDG). Maroc Med 1957;36:1295-6.

[14] Bodmer M, Meier C, Krahenbuhl S, et al. Metformin, sulfonylureas or other antidiabetes drugs and the risk of lactic acidosis or hypoglycemia: a nested case-control analysis. Diabetes Care 2008;31(11):2086-91.

[15] Mansfield R, Galea R, Brincat M, et al. Metformin has direct effects on human ovarian steroidogenesis. Fertil Steril 2003;79(4):956-62.

[16] Onken B, Driscoll M. Metformin induces a dietary restriction-like state and the oxidative stress response to extend C. Elegans Healthspan via AMPK, LKB1 and SKN1. PLoS One 2010;5(1):e8758. 
[17] Maruthur NM, Tseng E, Hutfless S, et al. Diabetes medications as monotherapy or metformin-based combination therapy for type 2 diabetes: a systematic review and meta-analysis. Ann Intern Med 2016;164(11):740-51.

[18] El-Mir MY, Detaille D, R-Villanueva G, et al. Neuroprotective role of antidiabetic drug metformin against apoptotic cell death in primary cortical neurons. J Mol Neurosci 2008;34(1):77-87.

[19] Saini N, Yang X. Metformin as an anti-cancer agent: actions and mechanisms targeting cancer stem cells. Acta Biochim Biophys Sin (Shanghai) 2018;50(2):133-43.

[20] Buzzai M, Jones RG, Amaravadi RK, et al. Systemic treatment with the antidiabetic drug metformin selectively impairs p53-deficient tumour cell growth. Cancer Res 2007;67(14):6745-52.

[21] Algire C, Amrein L, Zakikhani M, et al. Metformin blocks the stimulative effect of a high-energy diet on colon carcinoma growth in vivo and is associated with reduced expression of fatty acid synthase. Endocr Relat Cancer 2010;17(2):351-60.

[22] Li W, Wang QL, Liu X, et al. Combined use of vitamin D3 and metformin exhibits synergistic chemopreventive effects on colorectal neoplasia in rats and mice. Cancer Prev Res (Phila) 2015;8(2):139-48.

[23] Hosono $\mathrm{K}$, Endo $\mathrm{H}$, Takahashi $\mathrm{H}$, et al. Metformin suppresses azoxymethane-induced colorectal aberrant crypt foci by activating AMP-activated protein kinase. Mol Carcinog 2010;49(7):662-71.

[24] Moon HS, Mantzoros CS. Adiponectin and metformin additively attenuate IL1beta-induced malignant potential of colon cancer. Endocr Relat Cancer 2013;20(6):849-59.

[25] Nangia-Makker P, Yu Y, Vasudevan A, et al. Metformin: a potential therapeutic agent for recurrent colon cancer. PLoS One 2014;9(1):e84369.

[26] Zhang Y, Guan M, Zheng Z, et al. Effects of metformin on CD133+ colorectal cancer cells in diabetic patients. PLoS One 2013;8(11):e81264.

[27] Bekusova VV, Patsanovskii VM, Nozdrachev AD, et al. Metformin prevents hormonal and metabolic disturbances and 1,2-dimethylhydrazine-induced colon carcinogenesis in non-diabetic rats. Cancer Biol Med 2017;14(1):100-7.

[28] Zaafar DK, Zaitone SA, Moustafa YM. Role of metformin in suppressing 1, 2- dimethylhydrazine-induced colon cancer in diabetic and non-diabetic mice: effect on tumour angiogenesis and cell proliferation. PLoS One 2014;9(6):e100562.

[29] Jia Y, Ma Z, Liu X, et al. Metformin prevents DMH-induced colorectal cancer in diabetic rats by reversing the Warburg effect. Cancer Med 2015;4(11):1730-41.

[30] Geagea AG, Rizzo M, Jurjus A, et al. A novel therapeutic approach to colorectal cancer in diabetes: role of metformin and rapamycin. Oncotarget 2019;10(13):1284-305.

[31] Hosono K, Endo H, Takahashi H, et al. Metformin suppresses colorectal aberrant crypt foci in a short-term clinical trial. Cancer Prev Res (Phila) 2010;3(9):1077-83.

[32] Lee MS, Hsu CC, Wahlqvist ML, et al. Type 2 diabetes increases and metformin reduces total, colorectal, liver and pancreatic cancer incidences in Taiwanese: a representative population prospective cohort study of 800,000 individuals. BMC Cancer 2011;11:20.

[33] Sehdev A, Shih YC, Vekhter B, et al. Metformin for primary colorectal cancer prevention in patients with diabetes: a case-control study in a US population. Cancer 2015;121(7):1071-8.

[34] Currie CJ, Poole CD, Gale EA. The influence of glucoselowering therapies on cancer risk in type 2 diabetes. Diabetologia 2009;52(9):1766-77.

[35] Lee JH, Kim TI, Jeon SM, et al. The effects of metformin on the survival of colorectal cancer patients with diabetes mellitus. Int J Cancer 2012;131(3):752-9.

[36] Garrett CR, Hassabo HM, Bhadkamkar NA, et al. Survival advantage observed with the use of metformin in patients with type II diabetes and colorectal cancer. Br J Cancer 2012;106(8):1374-8.

[37] Fransgaard T, Thygesen LC, Gogenur I. Metformin increases overall survival in patients with diabetes undergoing surgery for colorectal cancer. Ann Surg Oncol 2016;23(5):1569-75.

[38] Cardel M, Jensen SM, Pottegard A, et al. Long-term use of metformin and colorectal cancer risk in type II diabetics: a population-based case-control study. Cancer Med 2014;3(5):1458-66.

[39] Spillane S, Bennett K, Sharp L, et al. A cohort study of metformin exposure and survival in patients with stage I-III colorectal cancer. Cancer Epidemiol Biomarkers Prev 2013;22(8):1364-73.

[40] Yakar S, Leroith D, Brodt P. The role of the growth hormone/insulin-like growth factor axis in tumour growth and progression: lessons from animal models. Cytokine Growth Factor Rev 2005;16(4-5):407-20.

[41] Kooijman R. Regulation of apoptosis by insulin-like growth factor (IGF)-I. Cytokine Growth Factor Rev 2006;17(4):305-23.

[42] Arcaro A. Targeting the insulin-like growth factor-1 receptor in human cancer. Front Pharmacol 2013;4:30.

[43] Lee J, Hong EM, Kim JH, et al. Metformin induces apoptosis and inhibits proliferation through the AMPactivated protein kinase and insulin-like growth factor 1 receptor pathways in the bile duct cancer cells. J Cancer 2019;10(7):1734-44

[44] Sridhar SS, Goodwin PJ. Insulin-insulin-like growth factor axis and colon cancer. J Clin Oncol 2009;27(2):165-7.

[45] Mogavero A, Maiorana MV, Zanutto S, et al. Metformin transiently inhibits colorectal cancer cell proliferation as a result of either AMPK activation or increased ROS production. Sci Rep 2017;7(1):159-92.

[46] Vallianou NG, Evangelopoulos A, Kazazis C. Metformin and cancer. Rev Diabet Stud 2013;10(4):228-35.

[47] Dutta D, Kalra S, Sharma M. Adenosine monophosphateactivated protein kinase-based classification of diabetes pharmacotherapy. J Postgrad Med 2017;63(2):114-21.

[48] Tomimoto A, Endo H, Sugiyama M, et al. Metformin suppresses intestinal polyp growth in ApcMin/+ mice. Cancer Sci 2008;99(11):2136-41.

[49] Park SY, Kim D, Kee SH. Metformin-activated AMPK regulates beta-catenin to reduce cell proliferation in colon carcinoma RKO cells. Oncol Lett 2019;17(3):2695702 . 
[50] Lei Y, Yi Y, Liu Y, et al. Metformin targets multiple signaling pathways in cancer. Chin J Cancer 2017;36(1):17.

[51] Wang SQ, Cui SX, Qu XJ. Metformin inhibited colitis and colitis-associated cancer (CAC) through protecting mitochondrial structures of colorectal epithelial cells in mice. Cancer Biol Ther 2019;20(3):338-48.

[52] Kalender A, Selvaraj A, Kim SY, et al. Metformin, independent of AMPK, inhibits mTORC1 in a rag GTPasedependent manner. Cell Metab 2010;11(5):390-401.
[53] Hirsch HA, Iliopoulos D, Struhl K. Metformin inhibits the inflammatory response associated with cellular transformation and cancer stem cell growth. Proc Natl Acad Sci U S A 2013;110(3):972-7.

[54] Sena P, Mancini S, Benincasa M, et al. Metformin induces apoptosis and alters cellular responses to oxidative stress in Ht29 colon cancer cells: preliminary findings. Int J Mol Sci 2018;19(5):1478.

[55] Kang S, Kim BR, Kang MH, et al. Anti-metastatic effect of metformin via repression of interleukin 6-induced epithelial-mesenchymal transition in human colon cancer cells. PLoS One 2018;13(10):e0205449. 